Erratum

\title{
Erratum to "Double-Blind, Randomized, Three-Armed, Placebo- Controlled, Clinical Investigation to Evaluate the Benefit and Tolerability of Two Dosages of IQP-AE-103 in Reducing Body Weight in Overweight and Moderately Obese Subjects"
}

\author{
Ralf Uebelhack, ${ }^{1}$ Udo Bongartz, ${ }^{1}$ Stephanie Seibt, ${ }^{2}$ Gordana Bothe, ${ }^{2}$ Pee Win Chong $\mathbb{D}^{3},{ }^{3}$ \\ Patricia De Costa $\mathbb{B}^{4},{ }^{4}$ and Natalia Wszelaki ${ }^{3}$ \\ ${ }^{1}$ Analyze \& Realize GmbH, Weißenseer Weg 111, 10369 Berlin, Germany \\ ${ }^{2}$ Analyze \& Realize GmbH, Waldseeweg 6, 13467 Berlin, Germany \\ ${ }^{3}$ Zaluvida Corporate Sdn Bhd, E-16 Plaza Mont Kiara, 2 Jalan Kiara, 50480 Kuala Lumpur, Malaysia \\ ${ }^{4}$ InQpharm Group Sdn Bhd, E-16 Plaza Mont Kiara, 2 Jalan Kiara, 50480 Kuala Lumpur, Malaysia \\ Correspondence should be addressed to Patricia De Costa; patricia@inqpharm.com \\ Received 8 May 2019; Accepted 12 May 2019; Published 11 July 2019 \\ Copyright ( $\odot 2019$ Ralf Uebelhack et al. This is an open access article distributed under the Creative Commons Attribution License, \\ which permits unrestricted use, distribution, and reproduction in any medium, provided the original work is properly cited.
}

In the article titled "Double-Blind, Randomized, ThreeArmed, Placebo-Controlled, Clinical Investigation to Evaluate the Benefit and Tolerability of Two Dosages of IQP-AE-103 in Reducing Body Weight in Overweight and Moderately Obese Subjects" [1], there was an error in the legend of Figure 3 that occurred during the production stage, as the color of the placebo results/bars has been replaced by the colors of the high dose results/bars and vice versa.

The correct version of Figure 3 should be as follows:

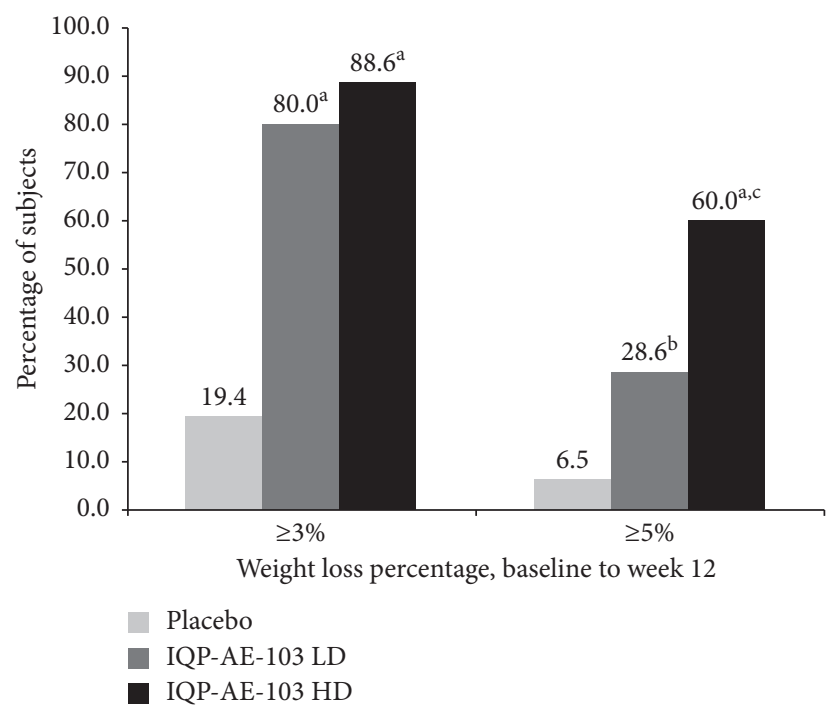

Figure 3: Responder rate for subjects who lost $\geq 3 \%$ and $\geq 5 \%$ of initial body weight at v6. $\mathrm{LD}=$ low dose; $\mathrm{HD}=$ high dose. ${ }^{\mathrm{a}} p<0.001$ vs. placebo; ${ }^{\mathrm{b}} p=0.026$ vs. placebo; ${ }^{\mathrm{c}} p=0.015$ vs. low-dose group. 


\section{References}

[1] R. Uebelhack, U. Bongartz, S. Seibt et al., "Double-blind, randomized, three-armed, placebo-controlled, clinical investigation to evaluate the benefit and tolerability of two dosages of IQP-AE-103 in reducing body weight in overweight and moderately obese subjects," Journal of Obesity, vol. 2019, Article ID 3412952, 12 pages, 2019. 


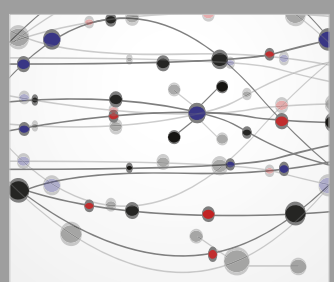

The Scientific World Journal
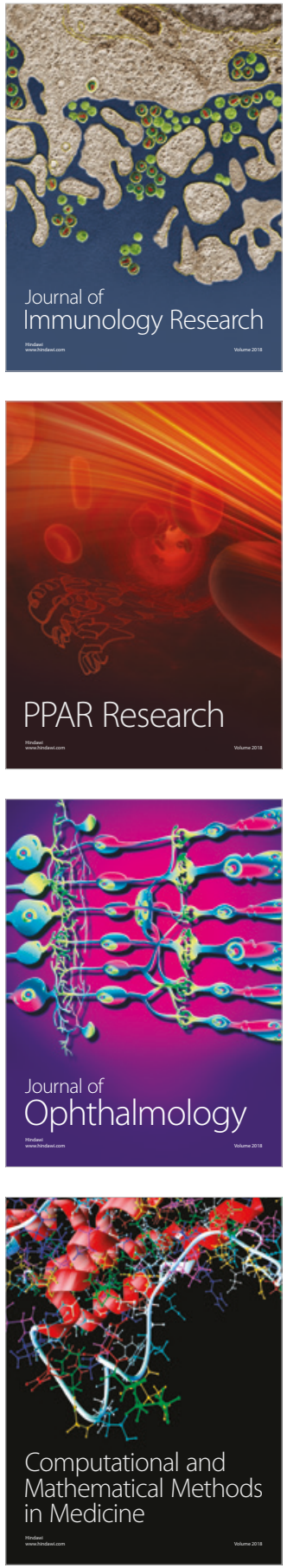

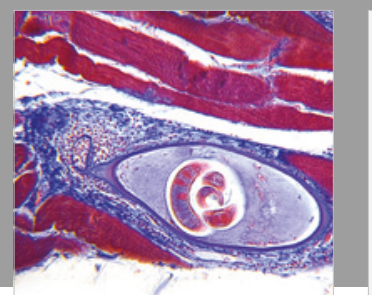

Gastroenterology Research and Practice

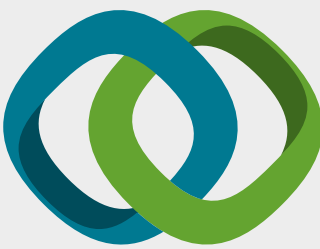

\section{Hindawi}

Submit your manuscripts at

www.hindawi.com
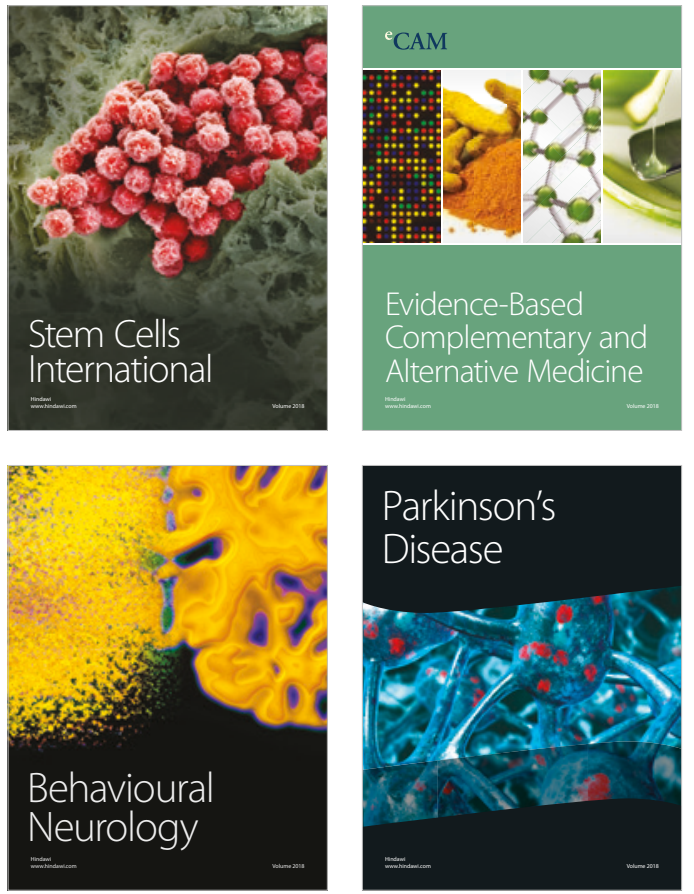

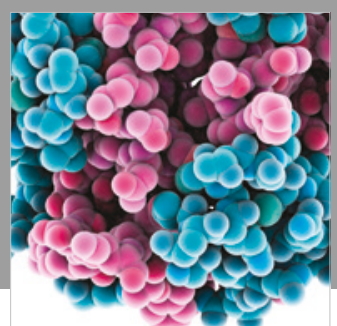

ournal of

Diabetes Research

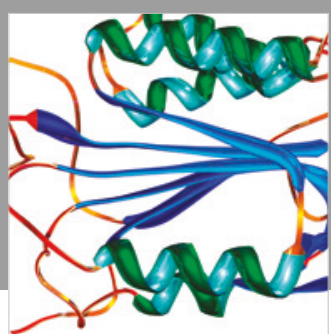

Disease Markers
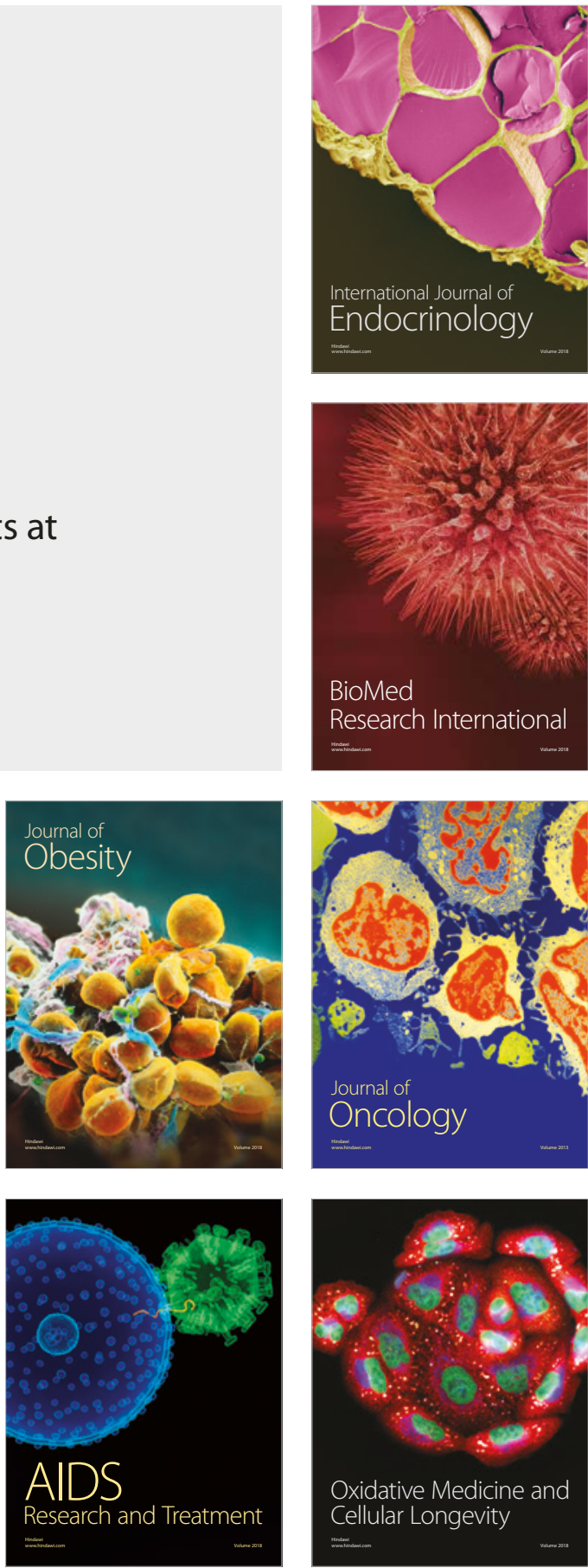